\title{
Studies Towards the Synthesis of Goniotrionin
}

\author{
Marco Antonio Barbosa Ferreira and Luiz Carlos Dias* \\ Instituto de Química - UNICAMP, P.O. Box 6154, 13084-971, Campinas, SP - Brazil. \\ *e-mail corresponding author: Idias@iqm.unicamp.br
}

Keywords: goniotrionin, Mukaiyama aldol, oxidative cyclization

\section{INTRODUCTION}

Annonaceous acetogenins are a class of natural polyketides which have promising anticancer, antiinfective, and pesticidal properties. Goniotrionin 1 is a potent antitumor agent which acts in $\mathrm{NADH}$ :ubiquinone oxirredutase. It was isolated in small amounts by McLaughlin et al. in 1998 from Annonaceae tree native to Thailand. ${ }^{1}$ To provide material for further biological studies as well as access to novel analogues, we initiated a study towards the synthesis of Goniotrionin.

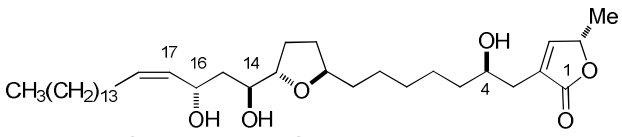

Scheme 1. Goniotrionin (1)

\section{RESULTS AND DISCUSSION}

Our approach began with construction of the C9C14 fragment (5). Epoxide ring-opening of 2 by allylmagnesium bromide led to the hydroxyalkene 3 ( $90 \%$ yield). Subsequent oxidative-cyclization of $\mathbf{3}$ according to Mukaiyama's protocol, ${ }^{2}$ provided transTHF 4 (73\% yield, ds >95:5). Oxidation of alcohol 4 followed by Wittig olefination provided iodide 5 (77\% yield in 2 steps, $Z: E>95: 5)$.

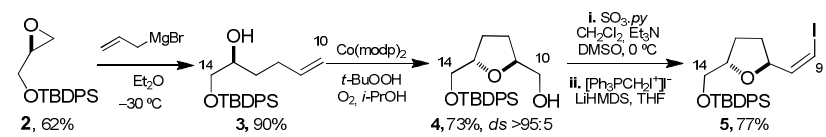

Scheme 2. Synthesis of iodide 5.

The next step involved epoxide ring-opening of glycidol 6 followed by protection of the hydroxyl group with a TBDPS protecting group leading the alkyne (7) (89\% yield). Sonogashira cross-coupling between 5 and 7 led to 8 in $82 \%$ yield. ${ }^{3}$ Reduction of enyne by $\mathrm{H}_{2} / \mathrm{Pd}-\mathrm{C}$ followed by deprotection of $\mathrm{PMB}$ with DDQ led to 9 in $73 \%$ yield. Next, treatment of alcohol 9 with $\mathrm{Tf}_{2} \mathrm{O}$ provided triflate 10. The $\mathrm{C}-\mathrm{C}$ coupling between triflate $\mathbf{1 0}$ and lactone $\mathbf{1 1}$ followed by oxidation of sulfide to the sulfoxide derivative with m-CPBA followed by thermal elimination led to butenolide 12 (54\% yield, 3 steps). Selective deprotection of TBDPS followed by alcohol oxidation provided aldehyde 13 (95\% yield, 2 steps).

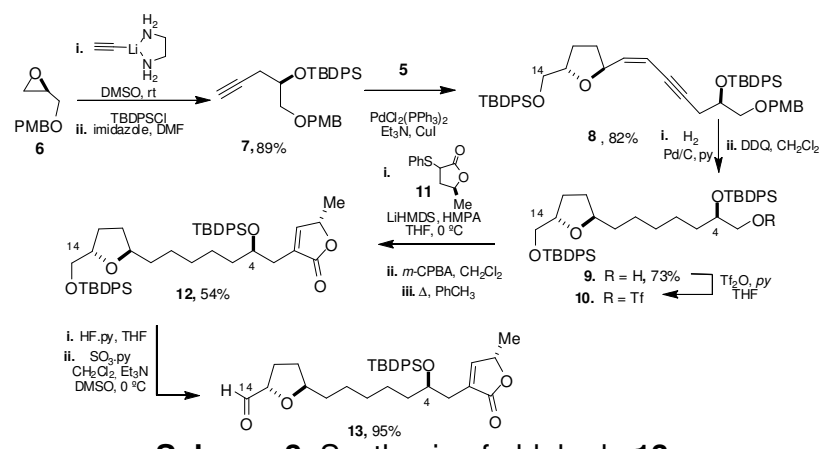

Scheme 3. Synthesis of aldehyde 13.

The construction of fragment $\mathrm{C} 15-\mathrm{C} 32$ started by oxidative cleavage of terminal alkene 14 in presence of catalytic amounts of $\mathrm{OsO}_{4}$ and $\mathrm{NalO}_{4}$ followed by Seyferth-Gilbert homologation providing alkyne 16 (90\% yield). ${ }^{4}$ Treatment of 16 with $n$-BuLi followed by Weinreb amide 17 provided methyl ketone 18 in $73 \%$ yield.

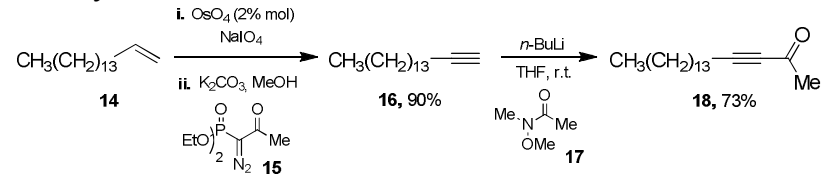

Scheme 4. Synthesis of methylketone 18.

Chelation controlled Mukaiyama aldol reaction between 13 and enolsilane 19 (obtained from 18) in the presence of $\mathrm{MgBr}_{2} \cdot \mathrm{OEt}_{2}$ provided 20 in $68 \%$ yield as one isomer.

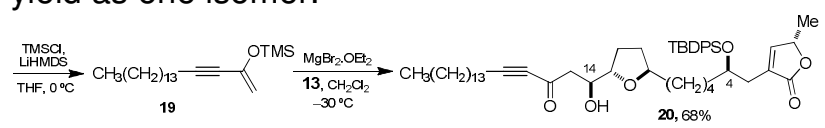

Scheme 5. Mukaiyama aldol reaction.

\section{CONCLUSION}

The synthesis of the C1-C32 fragment 20 of Goniotrionin (1) was achieved in 13 steps and $11 \%$ global yield. Studies aiming to confirmation of C14 stereochemistry are underway.

\section{ACKNOWLEDGEMENTS}

We are grateful to FAPESP for fellowships, CNPq, and CAPES for financial support.

\section{REFERENCES}

Alali, F. Q.; Rogers, L.; Zhang, Y; McLaughlin, J. L. Tetrahedron 1998, 54 5833

${ }_{2}^{2}$ Inoki, S.; Mukaiyama, T. Chem Lett. 1990, 67.

${ }^{3}$ Marshall, J. A.; Piettre, A.; Paige, M. A.; Valeriote, F. J. Org. Chem. 2003

${ }^{68}$ Müller, S.; Liepold, B.; Roth, G. J.; Bestmann, H. J. Synlett, 1996, 521. 